\title{
Diversity of Anopheles mosquitoes in Binh Phuoc and Dak Nong Provinces of Vietnam and their relation to disease
}

Chung Thuy Ngo ${ }^{1,2}$, Gregor Dubois ${ }^{1}$, Véronique Sinou ${ }^{3}$, Daniel Parzy ${ }^{3}$, Hong Quang Le ${ }^{4}$, Ralph E Harbach ${ }^{5}$ and Sylvie Manguin ${ }^{1 *}$

\begin{abstract}
Background: Human malaria is still a burden in Dak Nong and Binh Phuoc Provinces in south-central Vietnam that border Cambodia. Several Anopheles species that transmit human malarial Plasmodium may also transmit Wuchereria bancrofti, the nematode that causes Bancroftian lymphatic filariasis. The objective of this study was to investigate the role of Anopheles species in the transmission of these two pathogens in the two highly malaria endemic provinces of Vietnam.

Methods: Anopheles mosquitoes were collected in Dak Nong and Binh Phuoc Provinces in November and December of 2010 and 2011. Human landing catches, paired collections on human and buffalo, and resting captures were made with mouth aspirators. Collections were also made with light traps. Morphological and PCR-based methods were used to identify the species. Real-time PCR was used to detect Plasmodium species and $W$. bancrofti in individual mosquitoes.

Results: Twenty-four Anopheles species were identified among 797 captured mosquitoes. Anopheles dirus was found in both provinces and was the predominant species in Binh Phuoc Province; An. maculatus was the most prevalent species in Dak Nong Province. Anopheles minimus was collected only in Binh Phuoc Province. Some specimens of An. minimus and An. pampanai were misidentified based on morphology. Four specimens of An. scanloni were identified, and this is the first report of this species of the Dirus Complex in Vietnam. Two females, one An. dirus and one An. pampanai, collected in Binh Phuoc Province were infected with P. vivax, for an overall infection rate of $0.41 \%$ (2/486): $0.28 \%$ for An. dirus (1/361) and 20\% for An. pampanai (1/5). No mosquitoes were found to be infected with $P$. falciparum, $P$. knowlesi or $W$. bancrofti in either province.

Conclusion: A diversity of Anopheles species occurs in Dak Nong and Binh Phuoc Provinces of Vietnam, several of which are considered to be actual and potential vectors of malarial protozoa and microfilariae. It is highly likely that two of the species, An. dirus and An. pampanai, are active in malaria transmission based on the detection of $P$. vivax in females of these species. This is the first report of An. scanloni in Vietnam.
\end{abstract}

Keywords: Plasmodium, Wuchereria bancrofti, Anopheles, Vietnam, Real-time PCR

\footnotetext{
* Correspondence: sylvie.manguin@ird.fr

'Institut de Recherche pour le Développement (IRD), LIPMC, UMR-MD3,

Faculté de Pharmacie, F-34093 Montpellier, France

Full list of author information is available at the end of the article
} 


\section{Background}

Despite a decline in human malaria cases in Vietnam, malaria transmission continues in the forested areas of the southern and central provinces [1-5] where it is a significant public health and economic problem [6]. Several factors contribute to the maintenance of malaria transmission in this region of Vietnam, including a high density of the main vector Anopheles dirus [3,7,8], migration of people from malaria endemic areas [9] and failure to use preventive measures while working in the forest [10]. Moreover, use of insecticides and prophylactic drugs has resulted in resistance in some Anopheles species [11-13] and malarial parasites [14,15]. Furthermore, the monkey malarial protozoan Plasmodium knowlesi [16-21] has been found in both humans [7,22] and Anopheles mosquitoes in Vietnam [7,23]. Marchand et al. [7] reported co-infection of P. falciparum, P. vivax and P. knowlesi in an An. dirus female, indicating that $P$. knowlesi is most likely transmitted by the same primary vectors of $P$. falciparum and $P$. vivax. Hence, malaria caused by $P$. knowlesi may represent an additional challenge for malaria control in forested areas where $A n$. dirus and the natural hosts of $P$. knowlesi (macaque monkeys) co-occur, and zoonotic transmission of P. knowlesi could continue in the absence (or elimination) of $P$. falciparum and P. vivax.

Anopheles vectors involved in the transmission of Plasmodium parasites may also transmit Wuchereria bancrofti, the nematode that causes $90 \%$ of the lymphatic filariasis cases worldwide [24]. The co-occurrence of malarial and filarial parasites has been reported in endemic areas [25-28]. Unlike malaria, filariasis, a neglected disease, is rarely fatal but severe morbidity, including disabilities and adverse economic consequences due to disfigurement of limbs and male genitals (elephantiasis and hydrocele, respectively), occurs in $40 \%$ of infected individuals $[29,30]$. Bancroftian lymphatic filariasis occurs in the southern and central provinces of Vietnam [31,32], but little information is available about the co-infection of the microfilariae and malarial parasites in Anopheles mosquitoes. Even though Vietnam is now in the pre-elimination phase for the control of lymphatic filariasis [33], it is important to obtain additional information on the prevalence and transmission of this disease to better define its distribution in the country.

Binh Phuoc and Dak Nong Provinces are located in forested areas of south-central Vietnam. These two neighboring provinces share the border with Cambodia and are recorded as having the highest burden of malaria nationwide $[14,34,35]$. Although resistance of $P$. falciparum to the anti-malarial drugs chloroquine, sulfadoxinepyrimethamine and mefloquine has been reported in these provinces [14,15], no information concerning the transmission of malarial and filarial parasites is available.
To understand the role of Anopheles species in the transmission of Plasmodium and W. bancrofti, and document the diversity of the anopheline mosquitoes in Binh Phuoc and Dak Nong Provinces, we conducted medical entomological surveys in these provinces during 2010 and 2011.

\section{Methods}

Study area

Anopheles females were collected in two communes, $\mathrm{Bu}$ Gia Map in Binh Phuoc Province $\left(11^{\circ} 45^{\prime} \mathrm{N}, 106^{\circ} 43^{\prime} \mathrm{E}\right)$ and Dak Ngo in Dak Nong Province $\left(11^{\circ} 59^{\prime} \mathrm{N}, 107^{\circ}\right.$ $\left.42^{\prime} \mathrm{E}\right)$. Temperature in these provinces is around $25^{\circ} \mathrm{C}$ during the day and falls to $7-9^{\circ} \mathrm{C}$ at night; the rainy season extends from May to October and the dry season from November to April. The climate is favorable for agriculture, especially coffee, pepper and rubber. Crops of coffee, pepper or cashew nuts are usually grown around houses. The villages are surrounded by cassava, corn and rice fields, and are fringed by forest. The majority of income is from agricultural production. Every year, during harvest time, workers from neighboring regions come to work in the fields; hence, high population movement occurs in these areas. The wood houses are mostly built directly on the ground, but houses near forest or forest fringe are built on stilts. During harvest periods, people live in huts that provide little protection from mosquitoes.

Dak Ngo commune covers an area of 16,624 ha and has a population of 8,478 (in 2012), with ethnic minorities accounting for $65 \%$ of the residents. Annual incomes are low, $58 \%$ of households are poor. Transportation is difficult, especially during the wet season, because most roads are unpaved. Plantations have replaced most of the forest. In 2011, 24 malaria cases were reported in Dak Ngo, including 14 caused by P. falciparum and 10 due to $P$. vivax (data provided by the Dak Ngo community health station).

Unlike Dak Ngo, the roads in the Bu Gia Map commune are mostly paved and the area is mostly surrounded by primary forest, which includes the $\mathrm{Bu}$ Gia Map National Park. This commune covers an area of 2,330 ha, has 3,704 inhabitants (in 2009) and is a tourist destination. In 2011, 266 malaria cases were treated, 124 caused by $P$. falciparum, 138 due to $P$. vivax and four were mixed infections of $P$. falciparum and $P$. vivax (data provided by the Bu Gia Map community health station).

\section{Field collections and morphological identification of mosquitoes}

Four methods were used to capture mosquitoes: outdoor human landing catches, paired collections on human and buffalo and resting captures using mouth aspirators, and light trap collections. All collections were conducted from 17:00 until 07:00. The period of collections was the 
same during 2010 and 2011, during the change from the rainy to the dry season (November and December) when mosquito populations had peaked and a greater number of pathogen-infected females was anticipated. [It should be noted that limited and difficult access to the study sites prevented collections from being made during most of the rainy season.] Mosquitoes captured each hour by each method were retained in separate cups and labelled accordingly. Specimens were identified the following morning using the keys published by the National Institute of Malariology, Parasitology and Entomology [36,37], killed, divided into two parts, head-thorax (with legs and wings) and abdomen, and each part was stored separately at $-20^{\circ} \mathrm{C}$. The specimens were shipped on dry ice to the IRD laboratory in France and stored at $-80^{\circ} \mathrm{C}$ until further use.

In the Dak Ngo commune, mosquitoes were collected at six sites during nine nights in November 2010. During November and December 2011, no Anopheles mosquitoes were collected at these six sites; hence, an additional seventh collecting site was added where a few Anopheles were collected. These collections began at 17:00 and ended at midnight. The paired collections on human and buffalo were made at two sites by two collectors per site, one person performed human landing catches and another person made either resting captures or paired collections.

In the Bu Gia Map commune, human landing catches and light trap collections were made at three sites during 11 nights. Collections were made from 17:00 to 20:00. Three or four collectors seated about $10 \mathrm{~m}$ apart worked at each site. Two light traps were placed near the collection site.

\section{Ethical statement}

The Military Preventive Medicine Centre, Ho Chi Minh City (Vietnam) organized the field study and obtained all necessary permits. Vietnam People's Army Department of Military Medicine approved the study. Mosquito collections were done with the approval of the head of each village and the owner and occupants of the houses where mosquitoes were collected. Mosquito collectors gave their consent and were treated free of charge for malaria presumed illness throughout the study in accordance with the national drug policy of Vietnam.

\section{DNA extraction}

Genomic DNA was extracted from the head-thorax portions of mosquitoes using the Qiagen DNeasy Kit (Qiagen Ltd., Sussex, England). The manufacture's protocol was followed to obtain a final volume of $100 \mu \mathrm{l}$ of extracted DNA in TE buffer. Extracted DNA was divided and stored in separate tubes at $-20^{\circ} \mathrm{C}$ for sequencing and parasite detection.

\section{Molecular identification of Anopheles species}

Following morphological identification, DNA was extracted from Anopheles specimens belonging to groups and complexes of sibling species for which specific PCR identification methods are available, including the species of the Minimus Complex and closely related species such as An. aconitus, An. pampanai, An. varuna [38], the Dirus Complex [39], and the Maculatus Group [40]. Tfi DNA polymerase (Invitrogen, France) at 5 units $/ \mu$ l was used in all PCR assays. The PCR assay of Walton et al. [39] for the Dirus Complex was modified as follows: the final concentration of DMSO was reduced from $4 \%$ to $3.2 \%$, one unit of Tfi DNA Polymerase was substituted for 0.25 unit DNA Polymerase and $2 \mu$ of DNA template was used instead of $0.5 \mu \mathrm{l}$. The number of amplification cycles was also increased, from 32 to 35 . Positive controls for An. minimus, An. harrisoni, An. aconitus, An. pampanai, An. varuna, An. dirus, An. scanloni, An. baimaii, An. maculatus and An. sawadwongporni, available at LIPMC (IRD, Montpellier, France), were used as references.

\section{Sequencing}

Fragments of the mitochondrial genes (cytochrome oxidases 1 and 3, cox I and III) of Plasmodium, and fragments of the mitochondrial DNA (Cytochrome Oxidase subunits 1 and 2, COI and COII) and ribosomal DNA (Domain 3, D3, and Internal Transcribed Spacer 2, ITS2) of Anopheles mosquitoes were amplified and sent out for sequencing (Millegen, Labege Cedex, France). The fragments of cox III for P. falciparum and cox I for $P$. vivax were amplified using the PCR assay of Cunha et al. [41].

For Anopheles species, the D3 and ITS2 fragments of rDNA were amplified using the pair of primers of Sharpe et al. [42] and Beebe et al. [43], respectively. The $\mathrm{COI}$ and COII mitochondrial genes were amplified using the pair of primers described in Simon et al. [44] and Yang et al. [45], respectively. Standard protocols were used for all PCR amplifications. Each $50 \mu \mathrm{l}$ PCR reaction contained $5 \mu \mathrm{l}$ of 10X AccuPrime Pfx reaction mix, $1.5 \mu \mathrm{l}$ of each primer $(10 \mu \mathrm{M}), 0.4 \mu \mathrm{l}$ of AccuPrime Pfx DNA polymerase $(2.5$ units $/ \mu \mathrm{l})$ and $4 \mu \mathrm{l}$ of template DNA. Thermal cycling conditions consisted of an initial denaturation step at $95^{\circ} \mathrm{C}$ for $2 \mathrm{~min}$, then 40 cycles each consisting of denaturation at $95^{\circ} \mathrm{C}$ for $15 \mathrm{~s}$, annealing for $30 \mathrm{~s}$ at $50^{\circ} \mathrm{C}$ for COI, COII and ITS2 and at $63^{\circ} \mathrm{C}$ for D3, and extension at $68^{\circ} \mathrm{C}$ for $45 \mathrm{~s}$ with final extension at $68^{\circ} \mathrm{C}$ for $10 \mathrm{~min}$. The PCR products were kept at $4^{\circ} \mathrm{C}$ and checked by electrophoresis in 1.5\% agarose gel, containing gel red $1 \mathrm{X}$ at final concentration.

Successfully amplified products were purified using the Nucleo Spin DNA purification kit (Macherey Nalgen, Germany). Direct sequencing of the products in both 
directions was done with an ABI 377 automated sequencer (PE Applied Bio Systems, Warrington, England).

\section{Detection of Plasmodium species and Wuchereria bancrofti} using real-time PCR

LightCycler system 480 (Roche Applied Science, Penzberg, Germany) was used for the real-time PCR detection of sporozoites of three Plasmodium species ( $P$. falciparum, $P$. vivax and P. knowlesi) and the presence of Wuchereria bancrofti in the head-thorax portions of the mosquitoes. The sequences of the primers and probes used to amplify the target sequences were described by Rao et al. $[46,47]$ and Divis et al. [48], and are listed in Table 1. The Taqman probes were labelled with the reporter dyes FAM, HEX or Cy5 at the $5^{\prime}$ end, and the quencher dyes Black Hole Quencher 1 (BHQ1) and 2 (BHQ2) were added to the 3 ' end (detailed in Table 1). Primers and probes were commercially synthesized by Eurogentec (Angers, France). Extracted DNA used as positive controls for P. falciparum and $P$. vivax was provided by DP, and that used for Wuchereria bancrofti was provided by Dr. J. Pothikasikorn (Mahidol University, Bangkok, Thailand).

The real-time PCR mix was prepared using the Platinum Taq polymerase Kit for each PCR run. Total volume $(20 \mu \mathrm{l})$ of the mix containing (in final concentration) $1 \mathrm{X}$ PCR buffer, $4 \mathrm{mM} \mathrm{MgCl}_{2}, 200 \mu \mathrm{M}$ dNTP mixture, $0.225 \mu \mathrm{M}$ of each primer, $0.1 \mu \mathrm{M}$ of probe, 0.5 Unit Platinum Taq polymerase and $2 \mu \mathrm{l}$ of DNA template was used to fill a 384-well microplate (Roche Applied Science, Penzberg, Germany). Singleplex real-time PCR was preceded by positive and negative samples to detect the separated target and check the repeatability of the method.

Multiplex assays were designed to simultaneously detect several parasite species, e.g. Plasmodium species, $P$. vivax $+W$. bancrofti and P. falciparum + P. knowlesi.
Amplification consisted of one cycle of denaturation at $95^{\circ} \mathrm{C}$ for $15 \mathrm{~min}$ followed by 45 cycles at $95^{\circ} \mathrm{C}$ for $20 \mathrm{~s}, 60^{\circ} \mathrm{C}$ for $1 \mathrm{~min}$ and $40^{\circ} \mathrm{C}$ for $30 \mathrm{~s}$. Analysis of the singleplex and multiplex data was performed with the LightCycler 480 software (Roche Applied Science, Penzberg, Germany). PCR grade water was used as notemplate control. DNA from W. bancrofti, P. falciparum and $P$. vivax served as positive controls, and DNA extracted from human blood and An. dirus free of Plasmodium and W. bancrofti served as negative controls. All real-time PCR assays were carried out in duplicate, and samples that did not produce fluorescence before the threshold of 40 cycles $(\mathrm{Ct})$ were considered negative. Questionable samples with a single positive well were retested. Specimens that gave a positive signal for the presence of parasites in the real-time PCR before $40 \mathrm{Ct}$ were double checked using conventional PCR developed by Cunha et al. [41] for the detection of P. falciparum and $P$. vivax.

\section{Results}

Identification of Anopheles mosquitoes

A total of 797 Anopheles females were collected in Dak Nong and Binh Phuoc Provinces during November and December of 2010 and 2011. Morphological identifications showed that the specimens represented 20 species, including major malaria vectors of the Dirus Complex and the Funestus and Maculatus Groups (Table 2).

All specimens belonging to the Minimus Complex $(\mathrm{n}=83)$, Dirus Complex $(\mathrm{n}=390)$ and Maculatus Group $(\mathrm{n}=175)$ were processed for specific molecular identification. Misidentifications and discrepancies between morphological and molecular identifications occurred for specimens of each complex and group as shown in Table 2. Of the 83 specimens identified morphologically

Table 1 Sequences of primers and probes used for the detection of Plasmodium species and W. bancrofti using multiplex real-time PCR

\begin{tabular}{|c|c|c|}
\hline Name & Sequence $\left(5^{\prime}-3^{\prime}\right)$ & Target \\
\hline Plasmo 1 & GTTAAGGGAGTGAAGACGA TCAGA & Plasmodium sp. and $P$. knowlesi \\
\hline Plasmo 2 & AACCCAAAGACTTGATITC TCATAA & \\
\hline Plasprobe & FAM-ACCGTCGTAATCTTAACCATAAACTATGCCGACTAG-BHQ1 & \\
\hline Pk probe & HEX-CTCTCCGGAGATTAGAACTCTTAGATTGCT-BHQ1 & \\
\hline FAL_F & CTT TTG AGA GGT TIT GTT ACT TTG AGT AA & Plasmodium falciparum \\
\hline FAL_R & TAT TCC ATG CTG TAG TAT TCA AAC ACA A & \\
\hline$F A L \_P B$ & FAM - TGT TCA TAA CAG ACG GGT AGT CAT GAT TGA GTT CA - BHQ1 & \\
\hline VIV_F & ACG CTT CTA GCT TAA TCC ACA TAA CT & Plasmodium vivax \\
\hline VIV_R & ATT TAC TCA AAG TAA CAA GGA CTT CCA AGC & \\
\hline VIV_PB & HEX - TTC GTA TCG ACT TTG TGC GCA TIT TGC - BHQ1 & \\
\hline LDR1_F & ATT TTG ATC ATC TGG GAA CGT TAA TA & Wuchereria bancrofti \\
\hline LDR2_R & CGA CTG TCT AAT CCA TTC AGA GTG A & \\
\hline WB_PB & Cy5 - ATC TGC CCA TAG AAA TAA CTA CGG TGG ATC TCT G - BHQ2 & \\
\hline
\end{tabular}


Table 2 Anopheles species collected in Dak Nong (*) and Binh Phuoc (**) Provinces

\begin{tabular}{|c|c|c|c|}
\hline Complex/group & Taxa & $\begin{array}{l}\text { Morphological } \\
\text { identification }\end{array}$ & $\begin{array}{c}\text { Molecular } \\
\text { identification }\end{array}$ \\
\hline Annularis Group & An. philippinensis & 5 & - \\
\hline Asiaticus Group & An. asiaticus* & 1 & - \\
\hline \multirow[t]{3}{*}{ Barbirostris Group } & An. barbirostris** & 1 & - \\
\hline & An. barbumbrosus & 23 & - \\
\hline & An. campestris* & 5 & - \\
\hline \multirow[t]{3}{*}{ Dirus Complex } & An. dirus & 390 & 384 \\
\hline & An. scanloni** & 0 & 4 \\
\hline & Unidentified & 0 & 2 \\
\hline \multirow[t]{4}{*}{ Funestus Group } & An. aconitus** & 1 & 1 \\
\hline & An. minimus** & 83 & 78 \\
\hline & An. pampanai** & 0 & 5 \\
\hline & An. jeyporiensis** & 5 & - \\
\hline \multirow[t]{2}{*}{ Hyrcanus Group } & An. crawfordi* & 49 & 49 \\
\hline & An. nitidus & 2 & - \\
\hline Kochi Group & An. kochi & 18 & - \\
\hline Lindesayi Group & An. gigas* & 24 & - \\
\hline \multirow[t]{5}{*}{ Maculatus Group } & An. maculatus & 175 & 152 \\
\hline & An. sawadwongporni & 0 & 16 \\
\hline & An. rampae $e^{* *}$ & 0 & 6 \\
\hline & Unidentified & 0 & 1 \\
\hline & An. karwari** & 1 & - \\
\hline \multirow[t]{3}{*}{ Subpictus Group } & An. indefinitus** & 1 & - \\
\hline & An. subpictus & 4 & - \\
\hline & An. vagus* & 2 & - \\
\hline Tessellatus Group & An. tessellatus* & 4 & - \\
\hline Umbrosus Group & An. umbrosus* & 3 & - \\
\hline \multicolumn{2}{|c|}{ Total } & \multicolumn{2}{|c|}{797} \\
\hline
\end{tabular}

*Species collected in Dak Nong Province only; ${ }^{*}$ Species collected in Binh Phuoc Province only; No asterisk indicates species present in both provinces. Groups that include major malaria vectors are in boldface type. Molecular identification to species level is based on PCR assays available (only) for the Dirus Complex and the Funestus, Hyrcanus and Maculatus Groups.

as $A n$. minimus, five (6\%) were An. pampanai based on molecular analysis (Figure 1A). Among the 390 specimens identified initially as $A n$. dirus, DNA analysis showed that four (1\%) were actually specimens of An. scanloni (Figure 1B). Finally, of the 175 specimens identified morphologically as An. maculatus, molecular identification revealed the presence of three species: 152 An. maculatus (88\%), 16 An. sawadwongporni (9\%) and six $A n$. rampae (3\%) (Figure 1C).

In addition to the 20 species originally identified based on morphological characters, molecular identification revealed the presence of four other species, namely An. scanloni, An. pampanai, An. sawadwongporni and $A n$. rampae (Table 2). The dominant species was An. dirus (48\%), followed by An. maculatus (19\%) and
An. minimus (10\%) (Figure 2). These three species are the main malaria vectors in Southeast Asia, and represented $77 \%$ of the Anopheles females captured in the study sites in Dak Nong and Binh Phuoc Provinces. The other 21 species (180 specimens) represented $23 \%$ of the total collection (Figure $2 \mathrm{~A}, \mathrm{~B}$ ). Two specimens of the Dirus Complex and one of the Maculatus Group could not be identified by molecular methods (Figure 2). Of these 24 species, eight were commonly found in both provinces, whereas seven and nine species were only collected in Dak Nong or Binh Phuoc Province, respectively (Table 2).

Of the 311 specimens collected in Dak Nong Province, 308 were molecularly identified as members of 15 Anopheles species. Anopheles maculatus (48.7\%) and An. crawfordi (15.9\%) were the dominant species, followed by $A n$. dirus (7.5\%), which is considered the main vector of "forest malaria", An. gigas (8\%), An. barbumbrosus (7\%), An. kochi (5\%) and nine other species (8\%) - An. asiaticus, An. campestris, An. nitidus, An. philippinensis, An. sawadwongporni, An. subpictus, An. tessellatus, An. umbrosus and An. vagus, each of which was represented by $1-5$ specimens (Table 3 ).

Unlike Dak Nong Province, An. dirus (74\%) and An. minimus (16\%) accounted for $90 \%$ of the collections made in Binh Phuoc Province. These two species are known to be the main malaria vectors. Anopheles sawadwongporni, considered to be a secondary vector, represented $3 \%$ of the collections. Of the 17 species (486 specimens) collected in the province, 14 species ( $A n$. aconitus, An. barbirostris, An. barbumbrosus, An. indefinitus, An. jeyporiensis, An. karwari, An. kochi, An. maculatus, An. nitidus, An. pampanai, An. philippinensis, An. rampae, An. scanloni and An. subpictus) comprised only 7\% of the collections, each represented by six or fewer specimens (Table 3). Anopheles scanloni and An. rampae were only collected in Binh Phuoc Province. This is the first discovery of $A n$. scanloni in Vietnam and the first time $A n$. rampae has been found so far south in the country. Comparative analysis of DNA sequences from these two species showed a high degree of similarity with sequences of these species recorded in GenBank (http://www.ncbi. nlm.nih.gov/). The sequences for the Vietnamese species are deposited in GenBank under accession numbers KJ746968-KJ746995.

Detection of Plasmodium species and Wuchereria bancrofti A total of 765 Anopheles females were assayed for the presence of Plasmodium and W. bancrofti using a multiplex real-time PCR method with Taqman probes. One female of $A n$. dirus and one of $A n$. pampanai captured in Binh Phuoc Province were found to be infected with P. vivax (Figure 3A, B). The conventional PCR method of Cunha et al. [41] for parasite detection was used 


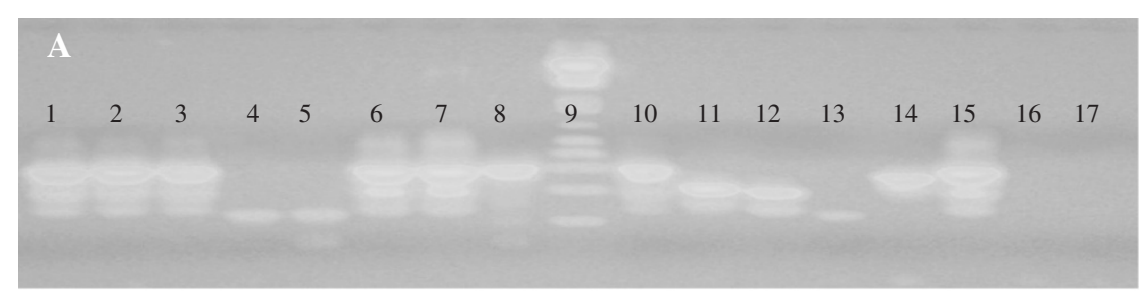

A - Lanes: 1-3, 6-8, samples of An. minimus; 4-5, samples of An. pampanai; 10-15, positive controls: 10, 15 of An. minimus (310 bp), 11 of An. aconitus (200 bp), 12 of An. harrisoni (180 bp), 13 of An. pampanai (90 bp), and 14 of An. varuna (260 bp); 9, $1 \mathrm{~kb}$ plus ladder; 16-17, negative controls.

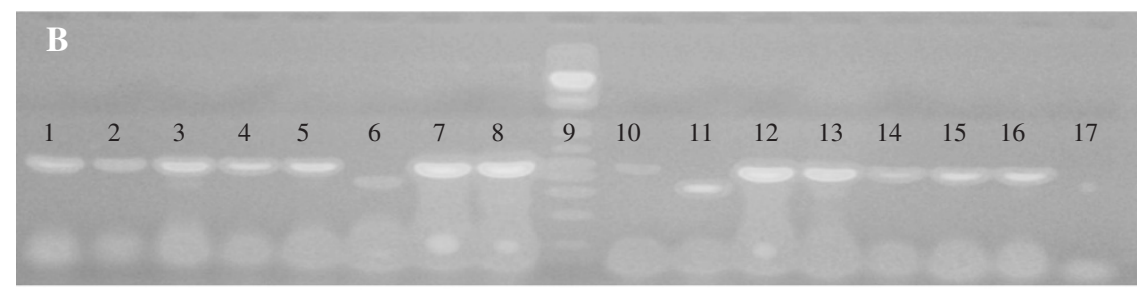

B - Lanes: 1- 5, 7, 8, 12-16, samples of An. dirus; 6, sample of An. scanloni; 10-11, positive controls: 10 of An. dirus (562 bp), 11 of An. scanloni (349-352 bp); 9, $1 \mathrm{~kb}$ plus ladder; 17, negative control.

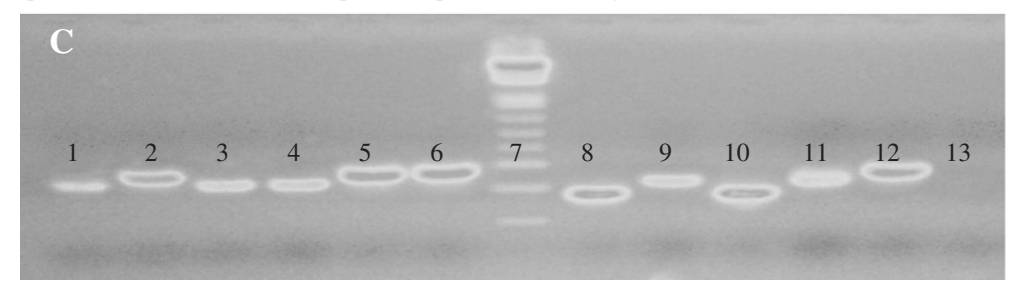

C - Lanes: 1, 3, 4, 11, samples of An. sawadwongporni; 10, sample of An. maculatus; 2, 5, 6, 12 - samples of An. rampae; 8-

9, positive controls: 8 of An. maculatus (180 bp), 9 of An. sawadwongporni (242 bp); 7, 1kb plus ladder; 13, negative control.

Figure 1 Multiplex allele-specific PCR products on 2\% agarose gel showing specimens of An. pampanai (A), An. scanloni (B) and An. rampae (C) collected in south-central Vietnam.

to confirm the infection of P. vivax (Figure 3C). The PCR products of the two $P$. vivax isolates were sequenced and both sequences detailed in Additional file 1 . Based on these results, the $P$. vivax infection rate in Anopheles specimens collected in Binh Phuoc was
0.41\% (2/486): $0.28 \%$ (1/361) for An. dirus and 20\% (1/5) for $A n$. pampanai (this high rate is due to the small number of specimens assayed and probably does not reflect the actual rate of infection in this species). None of the Anopheles specimens collected in the two provinces
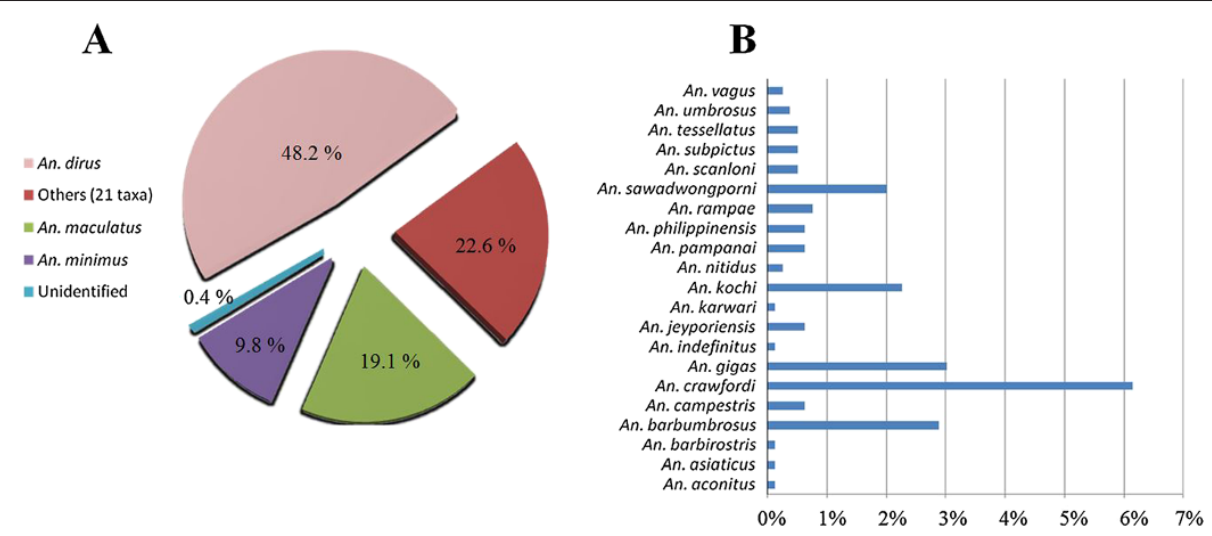

Figure 2 Anopheles species composition in south-central Vietnam based on molecular identification. (A) Prevalence of the malaria vectors and other taxa; (B) percentage of the "other" 21 species displayed in (A) (arranged alphabetically from bottom to top). 
Table 3 Specimens of the Anopheles species $(n=24)$ collected in Dak Nong and Binh Phuoc Provinces, Vietnam

\begin{tabular}{|c|c|c|}
\hline \multirow[t]{2}{*}{ Species } & \multicolumn{2}{|c|}{ Provinces } \\
\hline & Dak Nong & Binh Phuoc \\
\hline An. aconitus & & 1 \\
\hline An. asiaticus & 1 & \\
\hline An. barbirostris & & 1 \\
\hline An. barbumbrosus & 22 & 1 \\
\hline An. campestris & 5 & \\
\hline An. crawfordi & 49 & \\
\hline An. dirus & 23 & 361 \\
\hline An. gigas & 24 & \\
\hline An. indefinitus & & 1 \\
\hline An. jeyporiensis & & 5 \\
\hline An. karwari & & 1 \\
\hline An. kochi & 16 & 2 \\
\hline An. maculatus & 150 & 2 \\
\hline An. minimus & & 78 \\
\hline An. nitidus & 1 & 1 \\
\hline An. pampanai & & 5 \\
\hline An. philippinensis & 4 & 1 \\
\hline An. rampae & & 6 \\
\hline An. sawadwongporni & 3 & 13 \\
\hline An. scanloni & & 4 \\
\hline An. subpictus & 1 & 3 \\
\hline An. tessellatus & 4 & \\
\hline An. umbrosus & 3 & \\
\hline An. vagus & 2 & \\
\hline \multirow[t]{2}{*}{ Unidentified } & 3 & \\
\hline & 311 & 486 \\
\hline Total & & \\
\hline
\end{tabular}

Major malaria vector species are indicated in boldface.

were infected with $P$. falciparum, $P$. knowlesi or W. bancrofti, and none collected in Dak Nong Province were infected with $P$. vivax.

\section{Discussion}

Diversity of Anopheles mosquitoes in Dak Nong and Binh Phuoc Provinces

Vietnam, and Southeast Asia in general, is known to have the most diverse Anopheles fauna and the largest number of species complexes and groups anywhere in the world [49-51]. Anopheles dirus and An. minimus are recognized as the main vectors of malaria in Southeast Asia, but other species have been incriminated, including An. maculatus, An. sawadwongporni, An. sinensis, An. aconitus, An. pampanai, An. harrisoni, An. peditaeniatus and An. philippinensis [1,3-5,7,52]. The density of each species depends on the ecology of the area where transmission occurs [53-56]. One of the sibling species of the Dirus Complex, An. scanloni, is considered to be one of the primary vectors in southern Thailand, and it has also been reported in southern Myanmar, but until now it has not been found in other countries $[8,51,57]$. In Thailand, An. scanloni is considered to have a noncontinuous distribution because it is closely linked to limestone karst habitat [58], which has not been found in Vietnam (CTN, personal observation). Of the $390 \mathrm{fe}-$ males of the Dirus Complex included in the present study, four were molecularly identified as An. scanloni, the first record of this species in Vietnam. Of the eight species that comprise the Dirus Complex, three are now known to occur in Vietnam, i.e. An. scanloni, An. dirus and $A n$. aff. takasagoensis [59]. Although An. rampae of the Maculatus Group has been recorded in northern and north-central provinces of Vietnam (Lang Son, Ninh Binh, Nghe An and Quang Binh Provinces) [40,60], this is the first discovery of this species in the south-central region of the country. This species, An. maculatus and An. sawadwongporni are three species of the Maculatus Group that are known to occur in Vietnam. The Maculatus Group includes nine species in southern Asia that are difficult to distinguish morphologically due to overlapping anatomical characters [49], but despite this shortcoming they are considered to play a role in malaria transmission in several regions [51,61-63]. Anopheles maculatus and An. sawadwongporni, for example, have been implicated in malaria transmission in Vietnam [1,5]. Although four and six specimens of An. scanloni and An. rampae, respectively, were collected in the present study, this once again demonstrates the importance of accurately identifying Anopheles species, especially sibling species, and evinces the reliability of molecular assays for this purpose. This result also highlights the need for further studies to elucidate the occurrence and role of these two species in malaria transmission in Vietnam.

In addition to An. scanloni and An. rampae, we collected 22 species of Anopheles that were previously known to occur in Vietnam [1,3-5,53,64-66]. The Anopheles species composition in Dak Nong and Binh Phuoc Provinces included common species, but also species specific to each province. This species specificity is most likely linked to the ecology of the study sites. These two adjoining provinces, with similar climatic conditions, favor the presence of eight common Anopheles species. However, Dak Ngo commune in Dak Nong Province is mainly covered by secondary forest and large plantations of coffee, pepper, cashew nuts or cassava, with people living nearby these plantations to manage their crops. Many insecticides (agrochemicals) were administrated to protect the farm products and dams were constructed for irrigation (CTN, personal observation). These activities are resulting in ecological changes that may affect the 

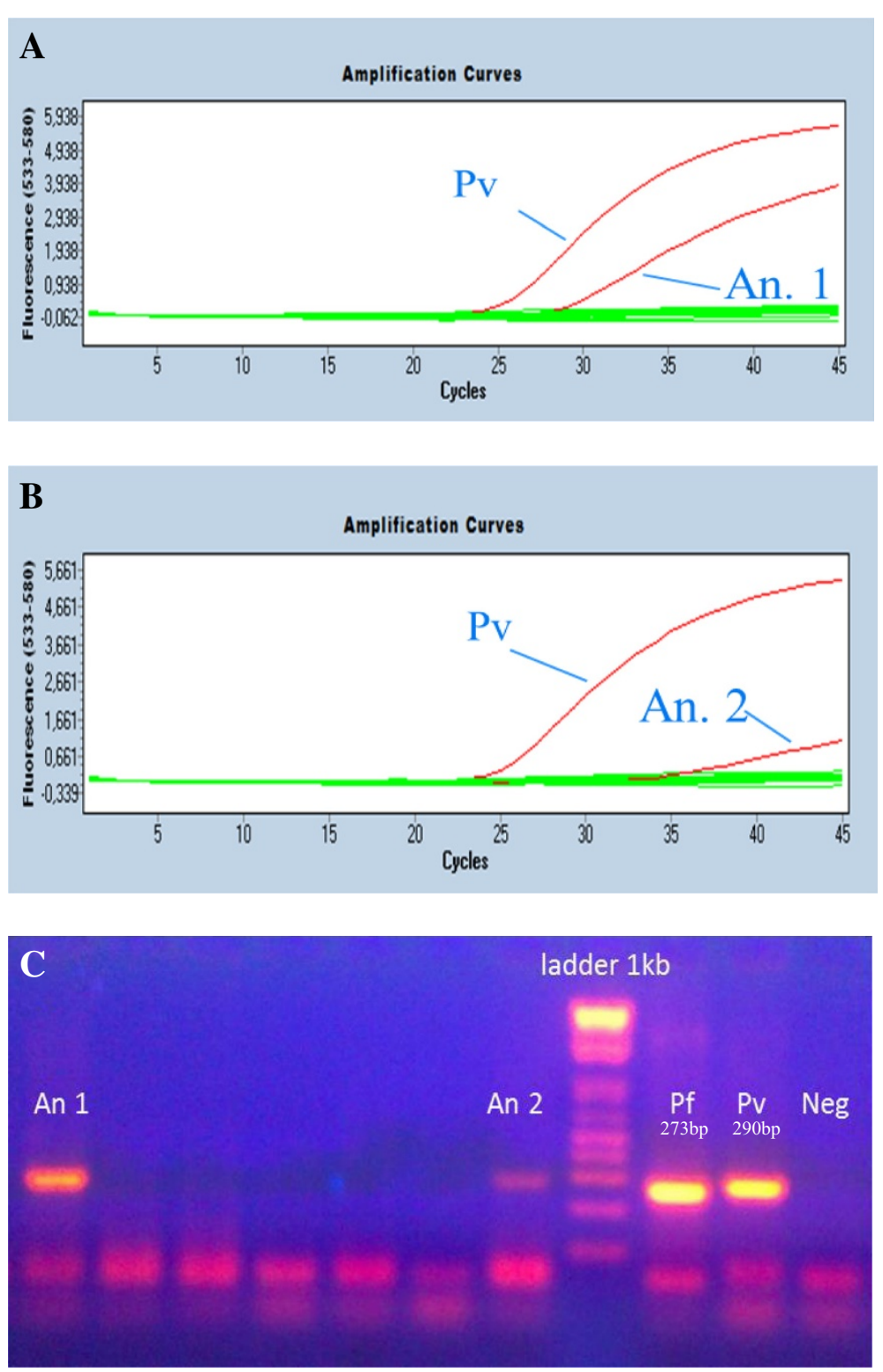

Figure 3 Amplification curves in the multiplex real-time PCR for two mosquitoes positive for P. vivax. (A) An. 1, Anopheles dirus; (B) An. 2, Anopheles pampanai; and (C) amplification of cytochrome oxidase cox I fragment by conventional PCR of $P$. vivax detected in Anopheles females collected in Vietnam. Pf and $\mathrm{PV}=$ positive controls for $P$. falciparum and $P$. vivax.

distribution of Anopheles species. In contrast, the study area of $\mathrm{Bu}$ Gia Map commune in Binh Phuoc Province is mostly covered by primary forest with natural and shaded streams, and this undisturbed tropical forest is known to favor the occurrence of primary malaria vectors, such as species of the Dirus Complex $[2,4,55,67]$. The distinctive environmental conditions of the two provinces influence the species composition of anophelines: $A n$. dirus and $A n$. minimus are the dominant species in Binh Phuoc Province whereas An. maculatus is dominant in Dak Nong Province. The presence of $A n$. dirus s.l. and
An. maculatus s.l is significantly correlated with sampling sites $\left(X^{2}=413.6, X^{2} \lim =3.84, P<0.00001\right)$. However, the objective of this study was not to examine the link between ecological conditions and Anopheles species composition, therefore further study is needed to confirm these results.

\section{Anopheles vectors and transmission of parasites}

The occurrence of malaria and lymphatic filariasis, two of the most common mosquito-borne parasitic diseases, the agents of which may be transmitted by the same 
vectors, was reported in Vietnam in the 1950s and 1970s [68-70], but no more recent studies have been conducted. The WHO considered lymphatic filariasis to be one of six infectious diseases that could be eradicated, and the regular surveillance of the disease and its vectors is mandatory to reach this goal [33]. Of the 24 Anopheles species identified in Dak Nong and Binh Phuoc Provinces during the present study, nine species (An. aconitus, An. barbirostris, An. dirus, An. maculatus, An. minimus, An. philippinensis, An. subpictus, An. tessellatus and $A n$. vagus) were previously considered to be potential vectors for co-transmission of Plasmodium and Wuchereria [24]. Two mosquitoes, one An. dirus and one $A n$. pampanai, were found infected by $P$. vivax but none were found infected with $W$. bancrofti, $P$. falciparum or $P$. knowlesi. The overall infection rate in Binh Phuoc Province was $0.41 \%$ (2/486), 0.28\% (1/384) for An. dirus and 20\% (1/5) for An. pampanai, and nil in Dak Nong Province. These results are in agreement with those reported by Nguyen in 2006 [31], who conducted a study of lymphatic filariasis in Khanh Hoa Province (located in south-central Vietnam east of Dak Nong and Bonh Phuoc Provinces) and reported that $3.64 \%$ of the population suffered from Bancroftian lymphatic filariasis; however, none of 144 An. vagus dissected were infected with $W$. bancrofti. Vietnam is one of the countries that have been considered to be in the pre-elimination phase of controlling lymphatic filariasis since 2011, and this study contributes to the surveillance of mosquitoes that potentially carry the parasite.

Cases of malaria reported in Vietnam are mostly due to P. falciparum (63\%). Plasmodium vivax accounts for almost all other cases (37\%) as $P$. malariae and $P$. ovale are seldom recorded [71] and a few cases attributable to P. knowlesi have been reported in south-central Vietnam [22]. A high proportion of asymptomatic cases, sometimes more than $80 \%$, have been found in some areas [72]. Recently, sporozoite positive Anopheles females have been reported in various northern, central and southern areas of Vietnam [1,3-5,7,53], with $A n$. dirus and An. minimus being the main malaria vectors. Besides these primary vectors, published reports also indicate the possible role of other Anopheles species, including An. pampanai, in malaria transmission $[3,5,7,23]$. The $P$. vivax infection rate in Binh Phuoc Province $(0.41 \% ; 2 / 486)$ is higher than the infection rate in the Anopheles population of Khe Ngang in Quang Binh Province $(0.24 \%$; 9/3,770) [1] and in seven species of Anopheles from Vietnamese and Cambodian populations $(0.08 \% ; 13 / 16,160)$ assayed by Durnez et al. [52]. However, it was lower than the infection rates previously reported by Marchand et al. [7] for An. dirus in Khanh Phu of Khanh Hoa Province infected with $P$. $\operatorname{vivax}(0.76 \% ; 43 / 5,663)$, Sanh et al. [4] for $A n$. dirus in Dong Thong of Ninh Thuan Province infected with $P$. falciparum $(0.67 \% ; 1 / 149)$ and Trung et al. [53] for An. minimus in Lang Nhot of Khanh Hoa Province infected with $P$. vivax $(0.83 \% ; 3 / 361)$. However, the infection rate of $A n$. pampanai in the present study was quite high $(20 \% ; 1 / 5)$, due to the paucity of specimens collected. Anopheles pampanai was incriminated as a vector of $P$. vivax in Vietnam prior to this study [5,52]. Durnez et al. [52] reported that $1.54 \%$ (1/65) of the An. pampanai females collected in Ninh Thuan Province were infected with $P$. vivax. As for the transmission of P. knowlesi in Vietnam, Marchand et al. [7] reported that $0.55 \%(31 / 5,663)$ of the An. dirus females collected in Khanh Phu of Khanh Hoa Province were infected with P. knowlesi. No Anopheles specimens were found to be infected by either P. knowlesi or $P$. falciparum in the present study; however, malaria cases are still reported in Dak Nong Province, and in a similar survey conducted in that province in 2007, using the conventional PCR method of Cunha et al. [41], we found that $2.03 \%(5 / 246)$ of the Anopheles females collected were infected with $P$. vivax: An. minimus (3/76) and An. maculatus (2/22) (CTN \& SM, unpublished data). Since this is the first study to examine Anopheles for co-infections of Plasmodium and W. bancrofti in south-central Vietnam, further study on a larger scale is needed to elucidate the role that different Anopheles species may play in the transmission of these parasites.

\section{Conclusions}

The Anopheles fauna of Dak Nong and Binh Phuoc Provinces comprises at least the 24 species that were collected and identified during the present study, including species found in both provinces and species specific to each province. The primary malaria vector, $A n$. dirus, was found in both provinces and was the dominant species in Binh Phuoc Province. Anopheles maculatus was the dominant species in Dak Nong Province but was scarce in Binh Phuoc Province. Anopheles minimus was only encountered in Binh Phuoc Province. This is the first report of the occurrence of $A n$. scanloni of the Dirus Complex in Vietnam, and the most southerly collection of $A n$. rampae of the Maculatus Group made in Vietnam thus far. No infections of $P$. falciparum, P. knowlesi or W. bancrofti were detected in 765 Anopheles females assayed. One An. dirus and one An. pampanai collected in Binh Phuoc Province were infected with $P$. vivax, giving an infection rate of $0.28 \%$ (1/384) for An. dirus, 20\% (1/5) for An. pampanai and an overall infection rate of $0.41 \%(2 / 486)$. Further study is needed to gain a better understanding of the vector status of different Anopheles species and their individual roles in malaria transmission in south-central Vietnam. 


\section{Additional file}

\section{Additional file 1: Sequences of Plasmodium vivax isolated in} Anopheles mosquitoes from Binh Phuoc, Vietnam.

\section{Competing interests}

The authors declare that they have no competing interests.

\section{Authors' contributions}

CTN designed the study, was involved in organising the fieldwork, participated in the field collections, conducted the analyses, interpreted the results, wrote and revised the manuscript. GD was involved in interpreting the results of molecular analyses and revising the manuscript. VS and DP were involved in organising the field work and revising the manuscript. HQL organised the field work and participated in the field collections. REH assisted with the identification of Anopheles crawfordi, reviewed the results and revised the manuscript. SM participated in the design of the study, interpretation of the results and supervised all stages of the work, including revising the manuscript. All authors read and approved the final manuscript.

\section{Acknowledgements}

We express our gratitude to the staff of the Department of Parasitology and Entomology of the Military Preventive Medicine Centre, Ho Chi Minh City, Vietnam, for organizing and participating in the fieldwork. CTN gratefully acknowledges Philippe Clair (qPCR platform, Faculty of Sciences, Montpellier) for his expert advice and help in conducting real-time PCR during the laboratory work in France. Fieldwork was funded by the Direction de la Coopération de Sécurité et de Défense, Ministry of Foreign Affairs, France. We are grateful to the personnel of the Military Mission, especially the Defence Attaché of the French Embassy in Vietnam, for logistical and administrative assistance. This study was made possible through support provided to CTN by IRD-DPF, Marseille, France.

\section{Author details}

${ }^{1}$ Institut de Recherche pour le Développement (IRD), LIPMC, UMR-MD3, Faculté de Pharmacie, F-34093 Montpellier, France. ${ }^{2}$ National Institute of Veterinary Research, Hanoi, Vietnam. ${ }^{3}$ UMR-MD3/IRBA, Faculté de Pharmacie, Aix-Marseille Université, F-13385 Marseille, France. ${ }^{4}$ Military Preventive Medicine Centre, Ho Chi Minh City, Vietnam. ${ }^{5}$ Department of Life Sciences, Natural History Museum, London SW7 5bD, UK.

Received: 28 February 2014 Accepted: 25 June 2014 Published: 9 July 2014

\section{References}

1. Do MC, Beebe NW, Van VN, Quang TL, Lein CT, Nguyen DV, Xuan TN, Ngoc AL, Cooper RD: Vectors and malaria transmission in deforested, rural communities in north-central Vietnam. Malar J 2010, 9:1-12.

2. Erhart A, Thang ND, Hung NQ, le Toi V, le Hung X, Tuy TQ, le Cong D, Speybroeck N, Coosemans M, D'Alessandro U: Forest malaria in Vietnam: a challenge for control. Am J Trop Med Hyg 2004, 70(2):110-118.

3. Marchand RP, Tuyen NQ, Hoanh NQ, Vien NT: The Khanh Phu Malaria Research Project. In Review Meetings 1-2 March 1996. Hanoi: Medical Publishing House; 1997:168.

4. Sanh NH, Van Dung N, Thanh NX, Trung TN, Van Co T, Cooper RD: Forest malaria in central Vietnam. Am J Trop Med Hyg 2008, 79(5):652-654.

5. Van Bortel W, Trung HD, Hoi LX, Van Ham N, Van Chut N, Luu ND, Roelants P, Denis L, Speybroeck N, D’Alessandro U, Coosemans M: Malaria transmission and vector behaviour in a forested malaria focus in central Vietnam and the implications for vector control. Malar J 1997, 9:373.

6. Morel CM, Thang ND, Xa NX, Hung le X, Thuan le K, Van Ky P, Erhart A, Mills AJ, D'Alessandro $U$ : The economic burden of malaria on the household in southcentral Vietnam. Malar J 2008, 7:166.

7. Marchand RP, Culleton R, Maeno Y, Quang NT, Nakazawa S: Co-infections of plasmodium knowlesi, P. Falciparum, and P. Vivax among humans and Anopheles dirus mosquitoes, southern Vietnam. Emerg Infect Dis 2011, 17(7):1232-1239.

8. Sinka ME, Bangs MJ, Manguin S, Chareonviriyaphap T, Patil AP, Temperley WH, Gething PW, Elyazar IR, Kabaria CW, Harbach RE, Hay SI: The dominant Anopheles vectors of human malaria in the Asia-Pacific region: occurrence data, distribution maps and bionomic precis. Parasit Vectors 2011, 4:89.
9. Pongvongsa T, Ha H, Thanh L, Marchand RP, Nonaka D, Tojo B, Phongmany P, Moji K, Kobayashi J: Joint malaria surveys lead towards improved crossborder cooperation between Savannakhet province, Laos and Quang Tri province Vietnam. Malar J 2012, 11:262.

10. Thang ND, Erhart A, Speybroeck N, Hung le X, Thuan le K, Hung CT, Ky PV, Coosemans M, D'Alessandro U: Malaria in central Vietnam: analysis of risk factors by multivariate analysis and classification tree models. Malar J 2008, 7:28.

11. Thang ND, Erhart A, Speybroeck N, Xa NX, Thanh NN, Ky PV, le Hung X, le Thuan K, Coosemans M, D'Alessandro U: Long-lasting insecticidal hammocks for controlling Forest malaria: a community-based trial in a rural area of central Vietnam. PLoS One 2009, 4(10):e7369.

12. Van Bortel W, Chinh VD, Berkvens D, Speybroeck N, Trung HD, Coosemans M: Impact of insecticide-treated nets on wild pyrethroid resistant Anopheles epiroticus population from southern Vietnam tested in experimental huts. Malar J 2009, 8:248

13. Van Bortel W, Trung HD, le Thuan $K$, Sochantha T, Socheat D, Sumrandee C, Baimai V, Keokenchanh K, Samlane P, Roelants P, Denis L, Verhaeghen K, Obsomer V, Coosemans M: The insecticide resistance status of malaria vectors in the Mekong region. Malar J 2008, 7:102.

14. Hien TT, Thuy-Nhien NT, Phu NH, Boni MF, Thanh NV, Nha-Ca NT, Thai Le H, Thai CQ, Toi PV, Thuan PD, Long Le T, Dong Le T, Merson L, Dolecek C, Stepniewska K, Ringwald P, White NJ, Farrar J, Wolbers M: In vivo susceptibility of Plasmodium falciparum to artesunate in Binh Phuoc Province Vietnam. Malar J 2012, 11:355.

15. Sinou V, Quang LH, Pelleau S, Huong VN, Huong NT, Tai LM, Bertaux L, Desbordes M, Latour C, Long LQ, Thanh NX, Parzy D: Polymorphism of Plasmodium falciparum $\mathrm{Na}(+) / \mathrm{H}(+)$ exchanger is indicative of a low in vitro quinine susceptibility in isolates from Viet Nam. Malar J 2011, 10:164.

16. Cox-Singh J, Davis TM, Lee KS, Shamsul SS, Matusop A, Ratnam S, Rahman HA, Conway DJ, Singh B: Plasmodium knowlesi malaria in humans is widely distributed and potentially life threatening. Clin Infect Dis 2008, 46(2):165-171.

17. Cox-Singh J, Singh B: Knowlesi malaria: newly emergent and of public health importance? Trends Parasitol 2008, 24(9):406-410.

18. Singh B, Kim Sung L, Matusop A, Radhakrishnan A, Shamsul SS, Cox-Singh J, Thomas A, Conway DJ: A large focus of naturally acquired Plasmodium knowlesi infections in human beings. Lancet 2004, 363(9414):1017-1024.

19. Vythilingam I, Noorazian YM, Huat TC, Jiram Al, Yusri YM, Azahari AH, Norparina I, Noorrain A, Lokmanhakim S: Plasmodium knowlesi in humans, macaques and mosquitoes in peninsular Malaysia. Parasit Vectors 2008, 1(1):26.

20. White NJ: Plasmodium knowlesi: the fifth human malaria parasite. Clin Infect Dis 2008, 46(2):172-173.

21. Ta TT, Salas A, Ali-Tammam M, Martinez Mdel C, Lanza M, Arroyo E, Rubio JM: First case of detection of plasmodium knowlesi in Spain by real time PCR in a traveller from Southeast Asia. Malar J 2010, 9:219.

22. Van den Eede $P$, Van HN, Van Overmeir C, Vythilingam I, Duc TN, Hung LX, Manh HN, Anne J, D'Alessandro U, Erhart A: Human Plasmodium knowlesi infections in young children in central Vietnam. Malar J 2009, 8:249.

23. Nakazawa S, Marchand RP, Quang NT, Culleton R, Manh ND, Maeno Y: Anopheles dirus co-infection with human and monkey malaria parasites in Vietnam. Int J Parasitol 2009, 39(14):1533-1537.

24. Manguin S, Bangs MJ, Pothikasikorn J, Chareonviriyaphap T: Review on global co-transmission of human Plasmodium species and Wuchereria bancrofti by Anopheles mosquitoes. Infect Genet Evol 2010, 10(2):159-177.

25. Muturi EJ, Jacob BG, Kim CH, Mbogo CM, Novak RJ: Are coinfections of malaria and filariasis of any epidemiological significance? Parasitol Res 2008, 102(2):175-181.

26. Burkot TR, Molineaux L, Graves PM, Paru R, Battistutta D, Dagoro H, Barnes A, Wirtz RA, Garner P: The prevalence of naturally acquired multiple infections of Wuchereria bancrofti and human malarias in anophelines. Parasito/ 1990, 100(Pt 3):369-375.

27. Chadee DD, Rawlins SC, Tiwari TS: Short communication: concomitant malaria and filariasis infections in Georgetown Guyana. Trop Med Int Health 2003, 8(2):140-143.

28. Muturi EJ, Mbogo CM, Mwangangi JM, Ng'ang'a ZW, Kabiru EW, Mwandawiro C, Beier JC: Concomitant infections of Plasmodium falciparum and Wuchereria bancrofti on the Kenyan coast. Filaria J 2006, 5:8. 
29. Molyneux DH: Control of human parasitic diseases: context and overview. Adv Parasitol 2006, 61:1-45.

30. Mathers CD, Ezzati M, Lopez AD: Measuring the burden of neglected tropical diseases: the global burden of disease framework. PLoS Negl Trop Dis 2007, 1(2):e114.

31. Nguyen DA: Study on Lymphatic Filariasis Characteristic in Khanh Vinh District, Khanh Hoa Province and Intervention Effectiveness. Thesis in Vietnamese. Hanoi: University of Medicine; 2006.

32. Meyrowitsch DW, Nguyen DT, Hoang TH, Nguyen TD, Michael E: A review of the present status of lymphatic filariasis in Vietnam. Acta Trop 1998, 70(3):335-347

33. WHO: Lymphatic Filariasis: A Handbook of Practical Entomology for National Lymphatic Filariasis Elimination Programmes. 1211 Geneva 27, Switzerland: WHO Press; 2013.

34. Abe T, Honda S, Nakazawa S, Tuong TD, Thieu NQ, le Hung X, le Thuan K, Moji K, Takagi M, Yamamoto T: Risk factors for malaria infection among ethnic minorities in Binh Phuoc, Vietnam. Southeast Asian J Trop Med Public Health 2009, 40(1):18-29.

35. IMPEQN: Malaria Situation in the Centre and Highlands Region: Statistic Data of 2012. Quy Nhon - Vietnam: Epidemiology deparment - Institute of Malaria, Parasitology and Entomology - Quy Nhon; 2013. 18 January 2013.

36. IMPE: Keys to Identify the Anopheles in Vietnam (Adult - Pupae - Larvae). Hanoi: Department of Entomology. Institute of Malariology, Parasitology and Entomology; 1987. Printed in the Hanoi Architectural University.

37. IMPE: Keys to Identify the Anopheles Mosquitoes (Adults-Pupae-Lavae). Hanoi: Department of Entomologie - Institute of Malariology, Parasitology and Entomology; 2008.

38. Garros C, Koekemoer LL, Coetzee M, Coosemans M, Manguin S: A single multiplex assay to identify major malaria vectors within the African Anopheles funestus and the Oriental An. minimus groups. Am J Trop Med Hyg 2004, 70(6):583-590

39. Walton C, Handley JM, Kuvangkadilok C, Collins FH, Harbach RE, Baimai V, Butlin RK: Identification of five species of the Anopheles dirus complex from Thailand, using allele-specific polymerase chain reaction. Med Vet Entomol 1999, 13(1):24-32.

40. Walton C, Somboon P, O'Loughlin SM, Zhang S, Harbach RE, Linton YM Chen B, Nolan K, Duong S, Fong MY, Vythilingam I, Mohammed ZD, Trung HD, Butlin RK: Genetic diversity and molecular identification of mosquito species in the Anopheles maculatus group using the ITS2 region of rDNA. Infect Genet Evol 2007, 7(1):93-102.

41. Cunha MG, Medina TS, Oliveira SG, Marinho AN, Povoa MM, Ribeirodos-Santos AK: Development of a Polymerase Chain Reaction (PCR) method based on amplification of mitochondrial DNA to detect Plasmodium falciparum and Plasmodium vivax. Acta Trop 2009, 111(1):35-38.

42. Sharpe RG, Harbach RE, Butlin RK: Molecular variation and phylogeny of members of the Minimus group of Anopheles subgenus Cellia (Diptera: Culicidae). Syst Entomol 2000, 25:263-272.

43. Beebe NW, Saul A: Dicrimination of all members of the Anopheles punctulatus complex by polymerase chain reaction - restriction fragment lengh polymorphism. Am J Trop Med Hyg 1995, 53:478-481.

44. Simon C, Frati F, Beckenbach A, Crespi B, Luiu H, Flook P: Evolution, weighting and phylogenetic utility of Mitochodrial gene sequences and a compilation of conserved of polymerase chain reaction primers. Ann Entomol Soc Am 1994, 87(6):251-285.

45. Yang $M, M a Y, W u$ J: Mitochondrial genetic differentiation across populations of the malaria vector Anopheles lesteri from China (Diptera: Culicidae). Malar J 2011, 10:216-224.

46. Rao RU, Atkinson LJ, Ramzy RM, Helmy H, Farid HA, Bockarie MJ, Susapu M, Laney SJ, Williams SA, Weil GJ: A real-time PCR-based assay for detection of Wuchereria bancrofti DNA in blood and mosquitoes. Am J Trop Med Hyg 2006, 74(5):826-832.

47. Rao RU, Huang Y, Bockarie MJ, Susapu M, Laney SJ, Weil GJ: A qPCR-based multiplex assay for the detection of Wuchereria bancrofti, Plasmodium falciparum and Plasmodium vivax DNA. Trans R Soc Trop Med Hyg 2009, 103(4):365-370.

48. Divis PC, Shokoples SE, Singh B, Yanow SK: A TaqMan real-time PCR assay for the detection and quantitation of Plasmodium knowlesi. Malar J 2010, 9:344.

49. Harbach RE: The Phylogeny and Classification of Anopheles. In Anopheles Mosquitoes - New Insights into Malaria Vectors. Edited by Manguin S. Rijeka, Croatia: InTech Open Access Publisher; 2013:3-55.
50. Manguin S, Boëte C: Global Impact of Mosquito Biodiversity, Human Vector-Borne Diseases and Environmental Change. In The Importance of Biological Interactions in the Study of Biodiversity. Edited by Lopez JP. Croatia: InTech Publisher; 2011:27-50.

51. Manguin S, Garros C, Dusfour I, Harbach RE, Coosemans M: Bionomics, taxonomy, and distribution of the major malaria vector taxa of Anopheles subgenus Cellia in Southeast Asia: an updated review. Infect Genet Evol 2008, 8(4):489-503.

52. Durnez L, Van Bortel W, Denis L, Roelants $P$, Veracx A, Trung HD, Sochantha $T$, Coosemans M: False positive circumsporozoite protein ELISA: a challenge for the estimation of the entomological inoculation rate of malaria and for vector incrimination. Malar J 2011, 10:195.

53. Trung HD, Van Bortel W, Sochantha T, Keokenchanh K, Quang NT, Cong LD, Coosemans M: Malaria transmission and major malaria vectors in different geographical areas of Southeast Asia. Trop Med Int Health 2004, 9(2):230-237.

54. O'Loughlin SM, Somboon P, Walton C: High levels of population structure caused by habitat islands in the malarial vector Anopheles scanloni. Heredity 2007, 99(1):31-40.

55. Manguin S, Carnevale P, Mouchet J, Coosemans M, Julvez J, Richard-Lenoble D, Sircoulon L: Biodiversity of Malaria in the World. Montrouge, France: John Libbey Eurotext; 2008.

56. Ali WN, Ahmad R, Nor ZM, Ismail Z, Ibrahim MN, Hadi AA, Hassan R, Lim LH: Environmental variables associated with immature stage habitats of culicidae collected in aboriginal villages in Pahang, Malaysia. Southeast Asian J Trop Med Public Health 2012, 43(6):1387-1399.

57. Baimai V, Kijchalao U, Sawadwongporn P, Green CA: Geographic distribution and biting behaviour of four species of the Anopheles dirus complex (Diptera: Culicidae) in Thailand. Southeast Asian J Trop Med Public Health 1988, 19(1):151-161.

58. Poopittayasataporn A, Baimai V: Polytene chromosome relationships of five species of the Anopheles dirus complex in Thailand. Genome 1995, 38(3):426-434

59. Takano KT, Nguyen NT, Nguyen BT, Sunahara T, Yasunami M, Nguyen MD, Takagi M: Partial mitochondrial DNA sequences suggest the existence of a cryptic species within the Leucosphyrus Group of the genus Anopheles (Diptera: Culicidae), forest malaria vectors, in northern Vietnam. Parasit Vectors 2010, 3:1-16

60. Morgan K, O'Loughlin SM, Mun-Yik F, Linton YM, Somboon P, Min S, Htun PT, Nambanya S, Weerasinghe I, Sochantha T, Prakash A, Walton C: Molecular phylogenetics and biogeography of the Neocellia Series of Anopheles mosquitoes in the Oriental Region. Mol Phylogenet Evol 2009, 52(3):588-601

61. Muenworn V, Sungvornyothin S, Kongmee M, Polsomboon S, Bangs MJ, Akrathanakul P, Tanasinchayakul S, Prabaripai A, Chareonviriyaphap T: Biting activity and host preference of the malaria vectors Anopheles maculatus and Anopheles sawadwongporni (Diptera: Culicidae) in Thailand. J Vector Ecol 2009, 34(1):62-69.

62. Wu S, Pan JY, Wang XZ, Zhou SS, Zhang GQ, Liu Q, Tang LH: Anopheles pseudowillmori is the predominant malaria vector in Motuo County, Tibet Autonomous Region. Malar J 2009, 8:46.

63. Singh S, Prakash A, Yadav RN, Mohapatra PK, Sarma NP, Sarma DK, Mahanta J, Bhattacharyya DR: Anopheles (Cellia) maculatus group: its spatial distribution and molecular characterization of member species in north-east India. Acta Trop 2012, 124(1):62-70.

64. Nguyen TA: Malaria in Vietnam. Environment, prevention and treatment. Bull Soc Pathol Exot 1993, 86(5 Pt 2):494-499.

65. Vu DC: Distribution of Anopheles Mosquito, the Malarial Transmission Vector in Some Forested Habitat, Located in Northern Part of Vietnam. Hanoi: IMPE-Hanoi; 2006:40.

66. Vu TP: Epidemiologie du Paludisme et Lutte Antipaludique au Vietnam Hanoï-Vietnam: Edition médicale; 1998.

67. Obsomer V, Defourny P, Coosemans M: The Anopheles dirus complex: spatial distribution and environmental drivers. Malar J 2007, 6:26.

68. Le Xuan C: Contribution to the study of malarial splenomegaly in Vietnam. Sang 1959, 30(1):13-25.

69. Hembree SC: Distribution and prevalence of Bancroftian filariasis in US Army Special Forces Camps in the Republic of Vietnam. Mil Med 1974, 139(4):309-312.

70. Colwell EJ, Armstrong DR, Brown JD, Duxbury RE, Sadun EH, Legters LJ: Epidemiologic and serologic investigations of filariasis in indigenous 
populations and American soldiers in South Vietnam. Am J Trop Med Hyg 1970, 19(2):227-231.

71. WHO: World Malaria Report. Geneva, Switzerland: WHO Press; 2012.

72. Thang ND, Erhart A, Hung leX, Thuan le K, Xa NX, Thanh NN, Ky PV,

Coosemans M, Speybroeck N, D'Alessandro U: Rapid decrease of malaria morbidity following the introduction of community-based monitoring in a rural area of central Vietnam. Malar J 2009, 8:3.

doi:10.1186/1756-3305-7-316

Cite this article as: Ngo et al:: Diversity of Anopheles mosquitoes in Binh

Phuoc and Dak Nong Provinces of Vietnam and their relation to

disease. Parasites \& Vectors 2014 7:316.

Submit your next manuscript to BioMed Central and take full advantage of:

- Convenient online submission

- Thorough peer review

- No space constraints or color figure charges

- Immediate publication on acceptance

- Inclusion in PubMed, CAS, Scopus and Google Scholar

- Research which is freely available for redistribution

Submit your manuscript at www.biomedcentral.com/submit
(O) Biomed Central 